\title{
Analysis Of Fundamental Factors In Planning And Teaching Conversation (keith s. Folse overview)
}

\author{
Khudriyah \\ Sekolah Tinggi Ilmu Tarbiyah Al-Urwatul Wutsqo Jombang, Indonesia \\ e-mail: azkiabilqis@gmail.com
}

\begin{abstract}
Conversation is part of speaking skill. Speaking is one of the English skill that must be taught since Junior High School. Teaching conversation needs hard work, the teachers should know everything related to the teaching. There are many factors influnce the teaching of conversation. According to Folse the one who has taught ESL / EFL for more than thirty five years in some countries. He has written many books on vocabulary, reading, speaking, writing, grammar, and listening, including the popular Great Writing series or Heinle Cengage. He has won many teaching and research awards said that there are five fundamental factors in planning and teaching conversation class such as learner's age, profeciency, level, and goal; the school curriculum; the topic being discussed; the two language in the task and for the task, and the activity serves as vehical for conversation.
\end{abstract}

Keywords: factors, planning, teaching, conversation, Keith S. Folse

\section{Background of Study}

English has been a global lingua franca, many countries in the world prioritize to master English, especially speaking skill. Many of them consider that learning a language, foreign or second language basically is learning speaking, even if learning language is not merely learning oral or spoken language. As R.A. Hall tells us that language is the institution whereby humans communicate and interact with each other by means of habitually used oral-auditory arbitrary symbols (Pride \& Holmes, 1972: 74).

Learning foreign languge encompasses four languge skills, they are listening, speaking, reading, and writing. In some context learning speaking to be the most important skill to be mastered. Such reasons are many language learners regard speaking ability as the measure of knowing a language; approaches and methods for teaching speaking have long been major focuses of language teaching 
Khudriyah

researches and conferences; recently a number of conversation and other speaking course books, audios and videos are published.

Conversation according to Chaney, A.L., and T.L. Burk (1998:13) is part of speaking skill. According to Chaney, speaking is the process of building and sharing meaning through the use of verbal and non-verbal symbols, in a variety of contexts. Mean while, Burns and Joyce (1992:2) say that speaking is so much a part of daily life that we tend to take it for granted . it means that unwittingly people do more speaking in dayly life. Besides, speaking is essential means of presenting communication among human beings. Therefore, people should be able to communicate successfully and acceptably.

In lin with Burns and Joyce, Widiati \& Cahyono (2006:69) explained that the growth of English as language for internal communication has made the teaching of speaking skill becomes very important. The importance of speaking skills is enormous for the learners of any language. Without speech, a language is reduced to a mere script. The use of language is an activity which takes place within the confines of community.

Speaking is an essential means of presenting communication among human beings, and people usually judge an individual in the way of he or she speaks. Besides, the non native learners do not get ample chances of meeting native speakers or visiting foreign countries. Therefore, people should be able to communicate successfully and acceptably. Furthermore, speaking is related to success in life, since it occupies an important position both individually and socially. Nunan said that to most people, mastering the art of speaking is the most important aspect of learning a second or foreign language, and success is measured in terms of the ability to perform a conversation in the language (Nunan D, 1991: 39).

Nevertheless, it is concidered difficult especially for foreign language learners because effective oral communication needs the ability to use the language appropriately in social interactions. Therefore, the speakers of a language need to be especially and purposefully trained in the skill of speaking. 
There are many advantages in mastering speaking skill, such as to improve the understanding of the current global conditions; the need for social life and understand human behavior is very important, then the language skills strongly support these needs; mastering speaking skill also enable people to create international network, and many others.

Teaching English as foreign language will be more difficult than as second language because the learners will be influenced by the environment which is they will not use English outside the classroom, so that the students will no longer keep their English very well. In second language the students are exposedto the target language both inside and outside the classroom all of the time, meanwhile in foreign language, they are exposed to the target language only in the classroom.

The environment is very influential in the learning of speaking. students who acquire English in school but it is not practiced at home, then their language will be lost. A conducive environment that supports students in using English as the language of communication, they will be able to increase the motivation of students in spurring them to increasingly use English in their daily lives.

The above phenomena shows that teaching speaking skill is very important, however, many language learners especially the learners of EFL classroom got difficulties in gaining the language, and it can be concluded the teaching of learning English is considered failed. This reasons requires teachers to gallop in improving the quality of teaching language especially speaking skill.

According to Folse (2006:9) there are five fundamental factors in planning and teaching conversation. They are: learners, curriculum, topic, the two language in and for the task, and the task serve as vehicle for conversation. And the following statements are the explanation of each.

\section{Discussion}

\section{Learners}

Learners are those who join in the classroom to participate in acquiring the target language, they are different each other they have different characteristic, cultural background, proficiency level, goals, etc. Knowing the learners, is an attitude should be done by teachers, so that they can know the students' desire for 
consideration in the preparation of appropriate programs for them, so the learning activities will be able to meet the students needs and interests. Student is God creator who has individual differences because of innate factors or the neighborhood he or she lives (Samsul Nizar, 2002:48-49).

Understanding the character of the students is a difficult thing, but their character can be seen from the way he or she's spoken, act and behave. All activities are visible is the embodiment of student'scharacter, spirit and nature. One of the function of knowing students character is the teacher will have real expectations of learners, for example, at what age the students begin to talk and begin to think abstractly or be known also at what age certain learners will acquire special skills and emotional behavior.

Teachers as educators and trainers to the learners, required to understand more about various aspects of his or her behavior and the behavior of people who are associated with his or her duties, especially the behavior of learners in all its aspects so that it can carry out its duties and role effectively, then it can make a real contribution to the achievement of the education goals.

Related to lerners, some things that the teachers need to know about their students, the first is learners' age. Age is very important thing to be considered in teaching, because by knowing the students age the teachers may decide what and how to teach their students based on their needs, wants, characteristics, etc. As delivered by Harmer that age is a major factor in the decision about how and what to teach (Harmer, 2002:37).

The students up to ten tend to play, they have little concentration means they can not stand in listening someone speaking in long time, they can stand not more than ten minutes.based on the observation in some places and based on the teaching experience, the writer saw many students under ten can be silent not more than 5 minutes. They felt anxiety and suppressed when the teacher asked them to keep silent even listening to her or his explanation. Someof them tend to speak by them selves, and when the teacher reminded them they felt anxiety.

He then explains that Young children who up to age of nine or ten has the following characteristic; they respond to meaning when they can not understand 
individual words; they more learn indirectly; their understang comes not only from explanation but also from see, hear, touch, and interact with. They need an individual attention and approval from teachers; they keen to tell about themselves and their own lives as main topic in the classroom. So the teacher have to involve them in the teachingand learning process. They have limited attention span. As teacher, they should pay attention about it and will not press them to concentrate for the teaching process. In this case the teachers must make good decision in teaching them, such as the method, media, models, etc.

The above explanation is different with adult. Adult learners can engage with abstract thought, they have life experience to draw on, they have high dicipline, understanding, and they come to the class with their experience has prepared. That's why good teachers will take the factors above in to account.

The second is learner's proficiency level. There are three levels of learner, such as beginner, intermediate, and advanced. Based on the learners level, the teachers should seperate them based on their level when they teach speaking, because they will get more difficulty in joining the class for all levels.

The third is the learners goal. Knowing the goal of learning speaking is very important. The teachers can make decision in conducting teaching process. Thera many goals of learning speaking, such as: to improve the learners spoken English skills and to enable them to communicate more effectively in English, so the teachers in teaching language skills should include the learning of intelligible pronunciation, stress and intonation patterns; listening comprehension skills; vocabulary beyond that of the subject matter; control of English grammar; paraphrasing and elaboration skills; coherent organization of information at sentence and discourse levels; interactive skills to enhance comprehension.

The other goal of learning speaking especially for EFL learners is to mastery the language especially for oral communication. To achieve this learning goal the teacher should guide students to speaking practice; the speaking activities should involve and motivate students; the teacher should give more attention and repitition especially for low abilities students; the teachers have to be able to 
Khudriyah

manage the class activity so that all students in the class have the equal participation (Journal of LE, vol 2, 2011).

What Folse found as his experience in teaching speaking there was various of individual characters, and there will be some broad categories that teachers be aware of as they teach speaking class. Ernest et all. In Fsolse (2006:12) said that "language teacher should know more about their students, the more teachers know about their students, the better they are able to shape the class based on the students' need, such as age, interests, motivation, cultural background, educational background, personality and language profeciency". However, It does not mean that the teachers will be succeed in teaching speaking class, but the teachers know some important aspects in teaching speaking, at least.

After knowing each students' differences, the teachers have to look for the method, strategy or technique, and preparing material which is able to cover all students to be active in speaking class. When the teachers find many differences and character, they can use small discussion as learning model, because small discussion which is consists of 3 or 4 members each group is easy to be controlled.When the students' differnces is not too large the teacher can use which may appropriate with them.

\section{Curriculum}

Curriculum can be said as planning of learning. Curriculum is sets of planning and role about content and learning material as guidence in teaching lerning activty curriculum decides what teachers have to teach to their students. Every school has curriculum which roles what teachers do to achieve the learning aim. In teaching speaking, the teacher may understand what curriculum wants, then they decide the step that must be done. According to Nana, curriculum is set of subjects and education program arranged based on foundations that must be delivered by teachers to their students (Nana Syaodih, 1997:4). In line with Nana, Nasution (2001:4) says that curriculum is the sum total of school's effort to influence learning whether in dayroom on the playground or out of school.

Basically curriculum in the broad sense serves as a guide or reference. For teachers, the curriculum serves as a guide in implementing the learning process. 
For principals and supervisors, curriculum serves as a guideline in carrying out the supervision or oversight. For parents, the curriculum serves as a guide to guide their children learn at home. For the community, the curriculum serves as a guide to provide assistance for the implementation of the educational process at school. As for the students, it functions as a learning curriculum. In the modern sense however, the curriculum is a statement about the quality of education that should be owned by the students after they were involved in the process and learning experience through the implementation of the curriculum. The quality above means the quality of education, learning process, strategy, materials to be prepared and done by schools and teachers.

According to Jihad, 2008: 24 the function of curriculum are:

a. First Adjustive or adaptive function is the ability to adapt to changes in their environment because it is dynamic that can be changed. For example in Indonesia, the education curriculum of Indonesia has been changed for tentimes and the last but not least is curriculum of 20013, and it will be changed if there is a reason for repairs. Speaking curriculum will be changed based on the change of the world.

b. The second is integrating function, the curriculum here as an adjustment implies that the curriculum is an educational tool that is capable of producing complete individuals who may be required and integrate in society. It means that curriculum is aimed to create personality who has good capability in the field that they joined on. Related to speaking, the students has been prepared to person who has real and perfect abilty in speaking.

c. The third is the diferentiating function means the curriculum serves as a tool that provides services of various differences in each student who should be respected and served. Every one has different characteristic and capability, curriculum respects it. Speaking teachers will prepare teaching method and strategy which able to reach across the gap of students without harming either party. 
Khudriyah

d. The forth is the propaedeutic function. this curriculum serves as educational tool that is capable of preparing students to a higher level, when they quit studying for example, they can live in the community. The speaking teachers in this case prepare the students to have speaking skill which can be used as stock alive, so they can afford a decent life with their speaking skill. They can open private course in the place they live, but if they continue their study it can support their learning process.

e. The fifth is the selective function. This curriculum function as providing an opportunity for students to determine study programs that match their interests and talents. Speaking teachers have to provide many method and strategy to make the students are intersted in. Much evidence showed that students chose programs because of their teacher in implementing teaching methods when they were in high schools.

f. The last is the diagnostic function. This fuction means as an educational tool that is able to direct and understand the students potential as well as their weaknesses. If the teachers have understood it, it is expected that students can develop the potential and improve weaknesses. In teaching speaking the teachers have to analyse the students characteristic, background, potensial and weaknesses to determine the steps in learning so that the learning objectives can be achieved.

Based on the above explanation the teachers have to take curriculum into account before teaching. They have to understand the content of curriculum, then design the syllabus, preparing materials needs and make planning to teach. The teaching success based on the implementing curriculum, so the curriculum must represent everything needed by the purpose of learning in this case is students' out put. Bedies, the teachers have to understand the type of program they are teaching.

Every school has program and aim in teaching speaking, for example teaching experienced by Folse in Saudi Arabia in which the purpose of speaking was the students pass the the test as soon as possible to get themselves to the United State for further training. And its curriculum incuded the text books and the tests was set up to achieve the goal of the program. That was focused on 
language component such as grammar and vocabulary. In this case the teachers can not change the curriculum to include speaking component. Folse then said that it would have been fruitless to attemp to do. (Folse, 2006:16).

Meanwhile his experience to teach in Japan was the students were taught more about hobby and culture in speaking. The purpose of teaching in Japan as his experience was the students wanted to learn litle English, to see foreigner, to know something about foreigner culture, and see meet other Japanese who have the same interest or educational level. It is difference with his students in Saudi Arabia who learn English to memorize information about the languge. This term is appropriate with what Richard points out that the development of curriculum is that a sound educational program should be based on an anlysis of students needs.

He suggested teachers who search teaching job to be aware of what school curriculum where the teachers will teach. They should know how progran can be set up whether individual or integrated skill classes. The teacher should know the different type program, whether it is match or no with the teacher philosophy of teaching speaking to avoid teacher unsatisfied in teaching.

\section{The Topic Being Discussed}

Teaching and learning speaking is different with math. The importance is the teacher in teaching speaking does not deviate significantly from the material to be taught. In this case the teacher choose the topic related to the material that is interesting for the students. The election topic has important role in influencing the students motivation in involving the teaching and learning process. If the students are highly motivated, then the class becomes live, on the other hand. However, it is difficult to have topic that please everyone. The Folse experience in selecting topic was by trying to stick general topic that is intersting his students of their age range.

The following are the requirements of good topic, such as; interesting, the topic being discussed is new and warm, it is mastered by learners, the topic is not too large, and it is not controversial. When the teacher has chosen the topic he should also consider the learners' age and the purpose of learning English. 
Khudriyah

a. The interesting topic.

Interesting topic can increase learners motivation in speaking, so they can speaking vigorously. On the other hand, when the topic is not interesting, the learners will be sleepy, lazy or they will ignore the subject. The teacher should make effort to choose the good topic because the learners will have high motivation when they discuss about it. Based on the writer experience, learners in some places dislike or feel taboo to discuss about an issue for example the learners from Islamic boarding school feel taboo when they discuss about violance like ripe and murder. That iswhy the teachers should choose an intersting topic.

Brwon, 2000; Nunan, 1996; Richard, 2001; Yorio,1986 in Folse explains that In learners syllabus, both teaching and practice material should centered arround the need the learners. It means if the topic is not interested them, the process of learning will not be succcesfull.

In line with interesting topic interesting learning is needed too. Though the topic is interseting meanwhile the learning is not, the learners will get nothing. Interesting learning is learning in which there is a story, there is singing, there are challenges, and there is compliance with the curiosity of students. Teacher relaxed and humorous, but serious in helping students master the subject matter in ways that is easy, fast, and fun. Teachers understand and comprehend the condition of students, as well as paying attention to the class. In addition, teachers also provide the opportunity for all students to grow and progress, not only on certain students.

b. New and warm topic.

It is important for teacher to choose New and warm topic in teaching, especially speaking will be waited by students, even young learners, because most of them like something that is new and warm. Every time there is always new and warm news, issues, and the teachers are able to take one or two of them as the most intersting and appropriate for their students. The students will loose their concentrate, motivation, or they will speak by them selves if the topic is oudated.before the teaching is done, the teachers should 
prepare their teaching as lesson plan or learning tools such as choosing warm, new and intersting and appropriate topic for them.

c. The Topic must be mastered by students.

The mastering topic for learners also makes them motivated, and this will be futile if the topic is interesting, warm, but they do not master it. Mastering topic can be done by knowing the issue from reading, watching or experiencing. In choosing topic the teacher should analyse the students mastery whether or not they can master the topic. Based on the writer experience in teaching speaking for religion university students, it was about politic. According to the writer politic was familiar for them because at that time all the channal of television and newspaper even people talked about the election. The students however, did not understand about it, so the class looked so died, and the learning process was not interesting anymore.

d. The topic is not too large.

One of the good topic is the topic is not too large. The large topic can make learners reluctant to speak up, because they need much time to prepare it. The teachers in electing topic have to pay attention the syllabus and indicators of learning then they choose the topic related the purpose of the study or the indicators to limit the widen topic.

e. The topic should not be controversial.

When the students find controversial topic with them, they usually will not be intersted in it. In the teaching and learning process the teachers must make the students enjoy so the aim of learning will be reached. In Indonesia the topic that has been controversial is sex education because the majority of schools agree that it is learned and most of them disagree. However, all of them can be done if there is approval between the school, parents and community.

f. The topic must be appropriate with the learners.

In line with topic, give attention to the learners' age and learning purpose is also crucial. When the topic is not suitable with learners' age, they are not interested in, they will be reluctant to join it, so they will get nothing. And 
Khudriyah

so the aim of study can't be reached when the topic is out of it. The young learners can't accept the topic of politic, polygamy, murder, etc, and the adult learners are reluctant to sing the children song. As teacher, they have to consider all needed by the learners.

According to Folse, the teacher in choosing topic can make list of 20 to 50 topic and the students can choose one of them. It is good the teacher will find good topic that fulfill the requirements. They are intersesting, appropriate with curriculum or students's age and need, mastered by students, and does not have controversial. So that the learning purpose can be reached.

Additionally Folse recommeds that factors that should be considered in choosing topic are learners age. Young learners can not accept high and serious topic, and the old dislike to sing and game. The next is the purpose of learning English. In selecting topik, the teachers should consider the purpose of learning, because the topic being discussed has to be appropriate with the purpose of learning. For example when the learning purpose is the students are able to speak about religion, the topic selected should relate to religion.

The third is the proficiency level of the learners. The low level learners can not be given difficult topic, and the high level learners will not be interseted in light topic. It is the teachers job to select the appropriate topic. The last is the learners' cultural bacground. Folse also explain that students cultural background affects topic choice, such as some students can talk about abortin, and some of them dislike. In other country talking about bombs, abortion, alcohol problem, women's right are not appropriate. However, in Indonesia the class is free talk about them, because it is teacher task as al Qur'an has said.

There are many classes which consists of variaous students with different level, proficiency and characters. In selecting topic, the teachers needs hard work. However, the teachers based on their expereriences can over come this matter, for instance selecting the general topic which appropriate for and interesting them. Besides, the teacher should show their capability in managing the class, such as make discussion or making small group in the class.

The Two Languages in the Task and for the Task 
Folse (2006: 23) explains that good conversation teachers know the components of the target language and they have to be able to construct lesson arround an important language component, and point out it within dialogue. When it is not done well, the teachers can not design activities that will widen their learners' current level of English. He also explains that the teacher must realize that there are two language require such as the language in the task and language for the task.

The language teacher, before teaching should prepare the vary tasks based on their students proficiency and age to be done by students before they speak up. In this case Folse had done when he taught, for instance he gave the task ( task in) before his students spoke up. In this case the students answered questions which would be used in speaking class (task for). The language teachers are able to do like what has been done by Folse. For example the language teachers may prepare tasks related to tenses to be done by their students before speaking class, then when they have spaeaking class thestudents can make conversation relate to the tenses has been done by thestudents before.

The function of giving tasks before speaking is to make speaking activity becomes life. The students will not be confused toward what they have to do in speaking class. There is comparison of two possible languages regarding the task. Folse (2006:25) said " when the teachers want their students to succeed in speaking task, they must give very careful thought to the language in the task as well as the language needed for the task".

The most common mistake in speaking class are the students do not know what to say, they are lack of vocabulary, the topic is not intersting. The students do not have self confidence, and the monotonous method in teaching process. That is why Folse recommended teachers to do what he has done.

The Task that Serve as Vehicle for Conversation

Clark (1996) says that conversations require attention from their participants for monitoring the topic and content, coordinating turn taking, and so on. Conversation is a progression of exchanges among participants. Each participant is a "learning system," that is, a system that changes internally as a 
Khudriyah

consequence of experience. This highly complex type of interaction is also quite powerful, for conversation is the means by which existing knowledge is conveyed and new knowledge is generated.

In line with Clark, CALD (2008) in Cambridge dictionary explains that conversation means talk between two or more people in which thoughts, feelings, and ideas are expressed, questions are asked and answered, or news and information is exchanged. It can be said that the learning success is based on the task given in the teaching and learning process.

Tasks can be regarded as the activities provided by the teacher to the students to be implemented during the learning process takes place so that the learning objectives achieved. Lee (2003:32), says that the task is an activity or exercise class that has a goal to be achieved only by the interaction between the participants, the task has a mechanism for sorting the arrangement and interaction, and focus on the meaning of the exchange; the taks also means an undertaking the learning effort of the la language that requires learners to grasp, manipulate, try hard, resulting in the target language because they do several sets of work plans.

Good teachers will think more about tasks activities. Such speaking teachers think about their students. They make effort to make their students able to master the material and have a good skill in speaking. Their mind almost immediately turn to what the students will do after presentation. The fact there are many students especially in Indonesia, after they learn foreign language in speaking class, they have nothing. Even they can not speak though little. This can be the teacher mistake in giving the tasks. To make the speaking clasroom sucsessful the teachers should prepare the task as good as possible.

Based on the Folse experience in teaching speaking in many countries, giving task has become fondamental factors in teaching speaking. According to him giving good task to learners helps them to improve their speaking skill ability, because by clear and appropriate task the learners can dig their capability through the task. He then explained that classes which assigned with specific tasks always do better than which are given more general assigmnet, because it can make students confused to determine topic, or the material become wider. 
Concrete task will involve students more than less specific task (Lee, K.W., et al. 2003).

Folse explained that one of skills that needed by good speaking teacher is the ability to choose topic, norrow it down to more specific topic then design the right kond of task. A medium topic which designed well will produce better class than good topic with medium task.

Doughty \& Pica, 1986 in Folse explain designing of effective task as significant role in the successful design of speaking activity, are:

1. Whether the task is one-way in which information exchange is optional or two-way task in which infor mation exchange is required

2. Whether learners are given time to plan what they might say in the task

3. Whether the solution in the task is open ended that are with several possible solutions, or restricted to one or finite set of answer.

One-way tasks means in the conversation the partners or listeners in speaking do nothing, they just listen what the speakers are saying. The information only flows in one direction. There is no required information exchange. Mostly the partners or listeners do not listen carefully. Such activities in one-way tasks is the teachers ask the students to tell a story or their experience. So this activity is not accordance with the meaning of above conversation.

On the other hand, in two-way task information exchange is required, so the conversation work can gain in more negotiation meaning. Long (1989) in Folse suggest that two-way tasks produce not only more negotiation work, but also more useful negotiation work. That is why two-way considered better than one-way task.

\section{Conclussion}

Based on the above expalanation, the writer can conclude that many factors influence the conversation activity. According to Folse based on his teaching conversation experience there are five crucial factors in planning and teaching conversation class. They are: (1) learner's age, profeciency, level, and goal. (2) the school curriculum. (3) the topic being discussed. (4) the two language in the task and for the task. (5) the activity serves as vehical for conversation. 
Khudriyah

\section{REFFERENCES}

Burns, A., \& Joice, H. Focus on Speaking. Sydney: NCLLTR Publications, 1999.

CALD. Cambridge Advanced Learner's Dictionary. Cambridge: Cambridge University Press, 2008.

Chaney, A.L., and T.L. Burk. Teaching Oral Communication in Grades K-8. Boston: Allyn\&Bacon, 1998.

Clark H.H \& EV Psychology and Language an Introduction to Psycholinguistics. New York. Harcourt. Brace, 1996.

Folse, Keith, S. The Eart of Teaching Speaking. Michigan. The University of Michigan Press, 2006.

Guidance for Learners' Improvement of Speaking Skills Doan Linh Chi Nha Trang Teachers Training College, Vietnam Language Education in Asia, Volume 2, Issue 2, 2011, 220).

Hall RA Jr. Pidgins and Creoles as standard languages in Pride and Holmes, 1972.

Harmer, J. How to Teach English. Cambridge: Addison Wesley Longman Ltd, 2002.

J.Agric. Food Chem., 51 (52), 729-7295.

Jihad, Asep \& Abdul Haris. Evaluasi Pembelajaran, Yogyakarta: Multi Pressindo, 2008.

Lee, K.W., Kim, Y.J., Lee, H.J., and Lee, C.Y., Cocoa Has more Phenolik, 2003.

Nana Syaodih. S. Pengembangan Kurikulum. Teori dan Praktik. Bandung: PT. Remaja Rosdakarya. 1997

Nasution, S. 2001. Pengembangan Kurikulum . Bandung: Alumni, 2001.

Nunan, D. Language Teaching Methodology: A Textbook for Teachers. New York: Prentice Hall, 1991.

Samsul Nizar, Filsafat Pendidikan Islam. Jakarta: Ciputat Press, 2002: 48-49

Widiati, U. \&Cahyono, B.Y. 2006. The Teaching of EFL in The Indonesian Context: The State of the Art. JurnalImuPendidikan, 13 (3): 139-150. 